\title{
EDUCAÇÃO, POLÍTICA E TRANSFORMAÇÃO SOCIAL: CONTRIBUIÇÕES A PARTIR DA TEORIA CRÍTICA
}

\author{
Franciele Bete Petry ${ }^{1}$ \\ Stefan Fornos Klein ${ }^{2}$
}

\section{Resumo:}

O presente artigo tem o objetivo de retomar alguns aspectos das contribuições para a relação entre a educação, a política, a democracia e os anseios de transformação social conforme expostos na teoria crítica, em textos de Karl Marx, Theodor W. Adorno e Max Horkheimer. Ele perpassa, nesse sentido, elementos trazidos por Marx especificamente no que diz respeito aos processos educacionais e formativos no âmbito da relação capital-trabalho para, então, percorrer brevemente alguns traços da maneira como as formas repressivas de educação e a sua relação face ao ideal burguês de formação (Bildung) se apresenta em textos e intervenções de Adorno, realizadas ao longo das décadas de 1950 e 1960, na Alemanha. Finalmente, conclui ao articular essas reflexões com aquelas apresentadas por Max Horkheimer, nesse mesmo período, ambas à luz do processo de reconstrução e redemocratização da Alemanha pós-nacionalsocialismo. Considera-se ser possível identificar, assim, contribuições relevantes para se pensar os processos educacionais, notadamente algumas de suas contradições, enfatizando a relevância premente da educação para a resistência, bem como indicando a relação explícita que tanto em Horkheimer quanto em Adorno está posta no que diz respeito à busca da democracia. Suas reflexões trazem as marcas indeléveis das formas de governo totalitárias que se disseminaram na Europa, sobretudo ao longo da primeira metade do século XX, e podem, em nossa interpretação, oferecer impulsos instigantes para que se examine os cenários contemporâneos, notadamente quando se considera o recrudescimento de sinais cada vez mais recorrentes de intolerância e perseguição política, religiosa e identitária em sentido mais amplo.

Palavras-chave: Educação. Formação (Bildung). Teoria Crítica. Transformação Social. Democracia.

\section{EDUCATION, POLITICS AND SOCIAL TRANSFORMATION: CONTRIBUTIONS FROM CRITICAL THEORY}

\footnotetext{
${ }^{1}$ Franciele Bete Petry é professora do Departamento de Filosofia da Universidade Federal de Santa Catarina. Doutora em Filosofia e em Educação (2011) pela Universidade Federal de Santa Catarina, realizou doutorado-sanduíche na Johann Wolfgang Goethe-Universität Frankfurt am Main, com bolsa CAPES/DAAD (2008/2010). Foi bolsista CAPES (2015/2016) durante a realização de estágio pósdoutoral na University College Dublin, Irlanda, processo n. ${ }^{\circ}$ 6730/14-0. Tem se dedicado à pesquisa de temas ligados à teoria crítica da sociedade, especialmente sobre estética e formação. E-mail: ffpetry@yahoo.com.br

2 Stefan Klein é professor do Departamento de Sociologia da Universidade de Brasília (SOL/UnB). Doutor em Sociologia (2012) pela Universidade de São Paulo (USP), realizou doutorado-sanduíche na Johann Wolfgang Goethe-Universität Frankfurt am Main, com bolsa do DAAD (2009/2010). Também realizou estadias de pesquisa, como bolsista do BMBF, na Albert-Ludwigs-Universität Freiburg im Breisgau. Os seus interesses de pesquisa estão voltados à teoria crítica da sociedade, à teoria sociológica, e à sociologia da educação, com ênfase sobre as configurações da educação superior e as mudanças no conceito de formação. E-mail: sfk@unb.br
} 


\begin{abstract}
:
The present article aims to retake a few aspects of the contributions that relate education, politics, and democracy, with a desire for social transformation, such as presented by critical theory, most notably in Karl Marx's, Theodor W. Adorno's, and Max Horkheimer's texts. In this sense, it passes through elements brought forward specifically in the work of Marx concerning educational and formative processes in the context of capital-labour relationship in order to, afterwards, briefly trace the manners under which repressive forms of education and their relations to the bourgeois ideal of formation (Bildung) present themselves in texts and interventions of Adorno, performed during the decades of 1950 and 1960, in Germany. Finally, it concludes by articulating these reflections with those presented by Max Horkheimer, during the same period, both developed under the light of the German process of reconstruction and redemocratization following national-socialism. That way, it is considered possible to identify chief contributions to think about educational processes, most notably regarding some of its contradictions, emphasizing the relevance of education for resistance, while, at the same time, indicating the explicit relationship exposed both in Horkheimer and Adorno concerning the pursuing of democracy. Their reflections are heavily marked by the totalitarian forms of government that disseminated themselves in Europe, especially during the first half of the $\mathrm{XX}^{\text {th }}$ century, and can, as far as we understand it, offer instigating impulses for contemporary reflections, mostly when the reawakening of signs of political, religious, and identity intolerance and persecution in a wider sense is considered.
\end{abstract}

Key Words: Education. Formation (Bildung). Critical Theory. Social Transformation. Democracy.

\title{
Introdução:
}

O texto a seguir busca apresentar uma reflexão, de caráter preliminar e com um objetivo introdutório, visando proporcionar à leitora e ao leitor um contato com alguns autores que, se frequentemente fazem parte do debate filosófico e sociológico, são o mais das vezes tratados separadamente, apesar de haver proximidades e fontes de diálogo profundas entre os seus argumentos. A temática geral organiza-se, assim, em torno da teoria crítica e do pensamento que tem início com Karl Marx e é retomada de maneira crítico-reflexiva pela assim chamada teoria crítica da sociedade, frequentemente referida como "Escola de Frankfurt"3. Tal movimento se constitui a

\footnotetext{
${ }^{3}$ A expressão "Escola de Frankfurt" veio a estabelecer-se apenas anos mais tarde, portanto foi cunhada por pessoas de fora do grupo, jamais tendo sido uma forma de auto-identificação até que, nos anos de 1960, essa alcunha tivesse se disseminado. Cabe salientar que a maior dificuldade em sua formulação consiste no fato de que o grupo nunca buscou ser uma escola, mas sim desenhar uma proposta teórica, e que, além disso, havia apenas uma unidade de pensamento bastante limitada entre seus integrantes, que tinham autonomia significativa para desenvolver o seu pensamento. Para mais detalhes a esse respeito, cf. Jay (1991) [1973] e Wiggershaus (2002) [1986].
}

\begin{tabular}{|c|c|c|c|c|}
\hline Govista Dialectus & Ano 4 & n. 10 & Janeiro - Julho 2017 & p. $91-114$ \\
\hline
\end{tabular}


partir de um grupo de intelectuais ligados ao Instituto de Pesquisa Social (Institut für Sozialforschung), em Frankfurt am Main, na Alemanha, a partir do final da década de 1920, mas cujos principais escritos datam primeiramente da década de 1930, ainda localizados na Alemanha, depois dos anos de 1940 (no exílio nos Estados Unidos da América), podendo-se destacar a obra Dialética do esclarecimento (1991) [1944/1947], escrita em coautoria por duas das figuras mais relevantes do grupo, Max Horkheimer e Theodor W. Adorno, e que finalmente, nos anos 1950 e 1960, voltam à Alemanha e a Frankfurt com o fim da Segunda Guerra Mundial e a ocupação do país.

Escolhemos, a fim de pensar a relação entre democracia e formação, o modo por meio do qual se problematizam questões ligadas à natureza e à história no enfoque da teoria crítica da sociedade e, mais especificamente, o seu olhar voltado para a educação enquanto papel mediador. Assim, o percurso será construído retomando sucintamente alguns aspectos da reflexão em Marx, notadamente nas discussões que ele, no âmbito da Associação Internacional dos Trabalhadores, realizou sobre a educação/formação politécnica. Em seguida, tentaremos estabelecer uma relação entre esse recorte e a teoria de outra figura fundamental no debate, Theodor W. Adorno, dedicando-nos, sobretudo, ao modo como ele concebe uma noção de educação política, tendo em vista um sentido emancipatório. Por fim, aprofundamo-nos no debate específico ligado aos argumentos de Alfred Schmidt e Max Horkheimer, apontando a importância do papel da filosofia e a relação com a prática em Marx, o que apenas pode ser apreendido a partir da formação social e da dominação humana, tal qual se fazem presentes na relação dialética que este - em conjunto com Engels - aborda em textos como A ideologia alemã.

\section{Apontamentos sobre o tema da educação em Karl Marx}

Ainda que o tema da educação tenha sido objeto de sua reflexão imediata apenas ocasionalmente, isso não pode ser equiparado a afirmar que essa temática assuma pouca relevância no pensamento de Marx. Tanto é que já no texto Teses sobre Feuerbach (Marx e Engels, 1958 [1845]) encontra-se uma reflexão voltada especificamente a pensar a questão de "quem educa os educadores" e a relação entre teoria e prática. O contexto do debate é aquele que desenvolve, esquematicamente e na forma de teses, um delineamento da crítica ao filósofo e teólogo alemão Ludwig Feuerbach, e que se volta, em especial, à maneira pela qual o seu pensamento se articula como um tipo de "materialismo religioso", de acordo com Marx e Engels. Face a isso, eles propõem e lhe

\begin{tabular}{|l|l|l|l|l|}
\hline Gonista Dialectus & Ano 4 & n. 10 & Janeiro - Julho 2017 & p. 91-114 \\
\hline
\end{tabular}


contrapõem uma visada materialista histórica e dialética. Conforme expresso na tese 3 do referido texto:

A doutrina [Lehre] materialista da transformação das condições e da educação do ser humano esquece que o próprio educador precisa ser educado. Ela precisa, por isso, cindir a sociedade em duas partes - das quais uma tem poder sobre a outra.

A coincidência da transformação das condições e da atividade humana ou da auto-transformação apenas pode ser apreendida e racionalmente compreendida como prática revolucionária [revolutionäre Praxis] (Marx e Engels, 1958 [1845], p. 5).

Logo, o que ambos buscam indicar é a maneira pela qual a educação, para ser pensada por um viés transformador, precisa compreender a prática revolucionária; com isso, tem-se as primeiras pistas para o que, adiante, será interpretado como um tipo de educação de caráter político em Adorno. Ao mesmo tempo, é necessário que se tenha uma noção abrangente de prática, ou seja, que se pense a atividade humana como orientada para a transformação e, desse modo, assuma um sentido político, sem que isso implique o reducionismo de imediatamente equiparar a prática revolucionária à violência: conforme veremos adiante, a questão reside precisamente em refletir acerca dos variados aspectos que devem estar presentes na transformação da existência humana. E, no esteio dessa reflexão, apresenta-se a necessidade de incorporar a dimensão do poder, que permite problematizar a relação entre democracia e formação.

Mais à frente, na tese de número 10, observa-se o desenvolvimento da maneira pela qual os autores refletem acerca da relação entre a natureza e o social, considerando que há de estar em pauta a forma de apresentação e organização do social, o que implica uma ideia de "todo" e, portanto, igualmente algum conceito de humanidade. Como afirmam Marx e Engels: "O ponto de vista do velho materialismo é a sociedade burguesa; o ponto de vista do novo materialismo é a sociedade humana, ou a humanidade social [gesellschaftliche Menschheit]" (Marx e Engels, 1958 [1845], p. 6).

Pouco mais de um século depois, uma linha de raciocínio muito semelhante estará presente na interpretação de Horkheimer. Referindo-se à relação entre ciência e Bildung (formação), ele destaca a perda da possibilidade do estudo geral face à especialização, e, desse ponto de vista, reflete sobre o sentido do conhecimento e da cientificização. Logo, podemos estabelecer um paralelo em relação à dicotomia velho e novo materialismo, que fundamenta o olhar de Marx, e notar a distinção entre um saber

\begin{tabular}{|l|l|l|l|l|}
\hline Q Ponista Dialectus & Ano 4 & n. 10 & Janeiro - Julho 2017 & p. 91-114 \\
\hline
\end{tabular}


mais amplo, que assume um caráter teórico, e o saber exageradamente especializado, com os seus efeitos deletérios. Isso desemboca, apesar de todas as limitações, numa tentativa de garantir espaço para a formação, conforme pode ser visto a seguir.

Quando o conhecimento passado, os pensamentos e os nexos do passado são esquecidos, então o conhecimento atual que resta se torna infinitamente mais exato, porém, mais pobre, e, como eu dizia, ele permanece abstrato, e os seres humanos são incapazes de realmente refleti-lo. É isso que a teoria precisa desempenhar: ela precisa ligar o passado ao presente e superar o nexo. Com isso chegamos novamente no conceito do qual partimos, a saber, o conceito de formação [dem Begriff der Bildung] (Horkheimer, 1989 [1967b], p. 182).

O cerne do argumento presente na contraposição entre o velho e o novo materialismo ${ }^{4}$ está no fato de que o horizonte de possibilidade e de realização humanas daquele estava limitado ao ponto de vista de apenas uma classe social, a burguesia, enquanto este, tal como Marx e Engels defendem, buscava realizar os anseios da sociedade, ou melhor, da humanidade como um todo, levando à formulação da humanidade social. Aqui, obviamente, a reflexão está marcada pelo antagonismo de classes que eles expõem no Manifesto do Partido Comunista (1998 [1848]). A perspectiva que eles assumem como aquela de caráter crítico, que leva em conta a história real e não a imaginada ou idealizada, precisaria contemplar os anseios e as necessidades humanas em geral, por isso, a humanidade social, e não apenas as exigências e necessidades de uma parcela limitada - e dominante - dos seres humanos. E, de modo comparável, o conhecimento, para Horkheimer - e, veremos adiante, igualmente para Adorno - deve ser generalizado, evitando que se restrinja tão somente a uma parcela da população. Isso significa, obviamente, que se a ciência no sentido dessa atividade cada vez mais especializada tem seu lugar por excelência na universidade, o conhecimento (Wissen) extrapola esse espaço formativo em especial, necessitando ser cada vez mais incorporado à formação, à educação em nível escolar.

\footnotetext{
${ }^{4}$ Pode-se notar a convergência interpretativa ao olhar para uma reflexão que Horkheimer apresenta por ocasião da disciplina "História do materialismo", que é ofertada por ele em 1957, na qual marca o aspecto de negação do materialismo, isto é, o olhar para uma sociedade cujo potencial se encontra no presente, porém, exige algumas mudanças para que possa ser concretizada. "Também no materialismo dialético, que enxerga a imagem natural como um produto a ser explicado pelas condições da sociedade, a ciência aparece como elemento mediados entre a sociedade e a realidade. Se o materialismo vulgar permanece aquele, que não ultrapassou o idealismo alemão, então o materialismo dialético se compreende a partir do idealismo como a sua consequência" (HORKHEIMER, 1989 [1957], p. 404).
}

\begin{tabular}{|l|l|l|l|l|}
\hline Q Povista Qialectus & Ano 4 & n. 10 & Janeiro - Julho 2017 & p. 91-114 \\
\hline
\end{tabular}


Nesse mesmo sentido é que se torna relevante destacar o papel desempenhado pela divisão do trabalho em sua interpretação crítica, tanto como processo histórico quanto conceito teórico. Primeiramente, ela adquire centralidade na medida em que sua origem pode ser encontrada, ainda que de maneira embrionária, nos núcleos familiares, por meio da divisão por gênero/sexo, ou de acordo com a força física das pessoas (Marx e Engels, 1958 [1845-1846], pp. 29 e segs.). Essa se encontra inteiramente separada do contexto específico da produção sob o jugo do capital. Mais à frente é que observará, e isso aparece discutido de maneira pormenorizada nos capítulos presentes em $O$ capital, sobre a cooperação e a divisão do trabalho (caps. 11 e 12), os efeitos peculiares que se apresentam como consequência do modo especificamente burguês ou capitalista, que se orienta preponderantemente para a produção de mercadorias, tendo como mediação a força de trabalho livre e assalariada. O desenvolvimento histórico incorporado em suas exposições questiona, assim, toda uma estrutura de corporações de ofício e formas das mais variadas quanto aos vínculos sociais, promovendo associações crescentemente imparciais, cuja mediação se dá por meio do dinheiro.

Tem-se, portanto, em A ideologia alemãa, as bases epistemológicas da perspectiva de Marx e Engels, quando afirmam: "Os pressupostos com os quais começamos não são arbitrários, não são dogmas, são os pressupostos reais, dos quais apenas podemos abstrair na imaginação. São os indivíduos reais, as suas ações e as suas condições materiais de vida, tanto as dadas quanto aquelas geradas por sua própria ação. Esses pressupostos, portanto, são constatáveis por meio da via puramente empírica" (Marx e Engels, 1958 [1845-1846], p. 20). Eis o viés materialista que nos ajuda a compreender a centralidade que conceitos como trabalho e divisão do trabalho - e, notadamente, os variados modos pelos quais são socialmente constituídos - ocupam na abordagem teórica desses autores.

Marx e Engels também estabelecem a importância de como se estruturam as relações sociais em meio à produção de uma determinada forma de sociedade 5 .

\footnotetext{
${ }^{5}$ Veja-se o tipo de relação com a natureza, e das formas de apropriação da natureza - questão cara a Alfred Schmidt e que reaparecerá na terceira parte de nosso texto - que medeiam e, assim, condicionam as relações sociais. "Pode-se distinguir os seres humanos dos animais pela consciência, pela religião, pelo que mais se quiser. Eles mesmos começam a distinguir-se dos animais, assim que começam a produzir os seus próprios meios de vida/alimentos [Lebensmittel], um passo condicionado por sua organização corpórea. Ao produzirem os seus próprios meios de vida/alimentos eles produzem, indiretamente, a sua vida material propriamente dita" (Marx e Engels, 1958 [1845-1846], p. 21). Esse processo de produção de sua vida material é que apenas pode ser compreendido à luz do fato de que os seres humanos, simultaneamente: (i) inserem-se na natureza e dependem dela para a sua sobrevivência e (ii) modificam a
}

\begin{tabular}{|c|c|c|c|c|}
\hline Rovista Dialectus & Ano 4 & n. 10 & Janeiro - Julho 2017 & p. $91-114$ \\
\hline
\end{tabular}


Refletindo acerca dos primórdios da humanidade e, portanto, da origem das formas sociais e de divisão das funções e do trabalho, afirmam: "Aqui vê-se logo: essa religião natural ou esse determinado comportamento face à natureza está condicionado pela forma social [Gesellschaftsform] e vice-versa. Aqui como alhures destaca-se também a identidade entre a natureza e o ser humano de tal maneira que a relação obtusa entre eles condiciona a sua relação obtusa com a natureza, justamente pois a natureza ainda foi pouco modificada historicamente e, de outro lado, que a consciência acerca da necessidade de relacionar-se com os indivíduos circundantes é o início da consciência a respeito de que ele vive em sociedade" (Marx e Engels, 1958 [1845-1846], p. 31). A consciência a respeito da vida em sociedade implicaria, em certa medida, a possibilidade de refletir sobre a democracia - ao mesmo tempo em que, dessa perspectiva, encontraremos, na teoria crítica, o modo de aprofundar esse olhar.

Conforme esboçado nas Teses sobre Feuerbach, esse conjunto de fatores está, indubitavelmente, permeado pelos efeitos e pelo processo da educação, haja vista que ela sempre está marcada pela forma social em que se insere. Logo, promover um sentido político emancipatório exigiria, também, abarcar os ditames desse processo social. Como é sabido, porém, Marx (2011 [1852]), tende a interpretar a democracia sempre no esteio de sua produção pela burguesia, ou seja, como democracia formal e abstrata.

Levando em consideração os argumentos apresentados, dediquemo-nos agora a expor os principais traços dos contornos da concepção de educação, preparação ou formação - no original alemão, Ausbildung - politécnica que Marx esboça. A questão da politecnia, conforme ele a entende, está ligada ao desenvolvimento multifacetado do indivíduo humano. No entanto, deve, ao mesmo tempo, enfrentar a condição específica e histórica de trabalhador(a) do modo como se encontra constituída na sociedade burguesa sob os anseios do capital. Assim, sua preocupação volta-se a desenhar e indicar as possibilidades de uma orientação que, de alguma maneira, possa fomentar essa pluralidade humana, porém, ainda tomando o trabalho como aspecto ou faceta fundamental e constitutiva do ser social, como posto n'A ideologia alemã.

O texto que focaremos a seguir, redigido em 1866 no contexto dos debates da Associação Internacional dos Trabalhadores, traz diferentes dimensões do problema e

si próprios ao modificarem a natureza e, consequentemente, produzem modificações na existência humana que apenas podem ser compreendidas por meio da atenção às mudanças sobre a natureza.

\begin{tabular}{|l|l|l|l|l|}
\hline Rovista Dialectus & Ano 4 & n. 10 & Janeiro - Julho 2017 & p. 91-114 \\
\hline
\end{tabular}


o faz no esteio da associação entre a teoria e a prática, ou seja, refletindo acerca das implicações e exigências de determinadas mudanças. Desse modo, e desculpando-nos pela extensa citação, apresentamos o cerne da questão por ele esboçada, quando afirma ${ }^{6}$ :

A parte mais esclarecida da classe trabalhadora compreende, porém, muito bem que o futuro de sua classe e, assim, o futuro da humanidade depende por inteiro da educação das gerações de trabalhadores em crescimento. Ela sabe que, sobretudo, as crianças e os trabalhadores adolescentes precisam ser protegidos das consequências nefastas do atual sistema. Isso apenas pode ser alcançado por meio da transformação da visada social [gesellschaftliche Einsicht] em poder social [gesellschaftliche Macht] e, sob as condições dadas, isso apenas pode ocorrer por meio de leis gerais, realizadas pelo poder estatal [Staatsgewalt]. Quando da realização dessas leis, a classe trabalhadora de modo algum fortalece o poder de governo [Macht der Regierung]. Pelo contrário, ela transforma aquele poder [Macht], que atualmente é usado contra ela, em seu próprio servo. Ela alcança, por meio de um ato legislativo geral, o que ela buscaria em vão por meio de uma multiplicidade de esforços individuais isolados.

Partindo dessa posição explicamos que não pode ser permitido, nem aos pais, nem aos empresários, empregar o trabalho de pessoas jovens, a não ser que ela esteja ligada à educação. Sob educação entendemos três coisas.

Primeiro, educação espiritual.

Segundo: educação física, como ela se encontra dada nas escolas ginásticas e através de exercícios militares.

Terceiro: educação politécnica [Polytechnische Ausbildung], que transmite os princípios gerais de todos os processos de produção e, ao mesmo tempo, introduz a criança e o jovem no uso prático e no manuseio de instrumentos elementares de todos os ramos do trabalho (Marx, 1992 [1866], p. 194-195) ${ }^{7}$.

Talvez o principal aspecto que aqui se pode observar consista no modo como se estrutura a relação entre uma educação geral e aquela educação que, quando Marx escreve, precisa dar conta da situação e composição da classe trabalhadora, de quem,

\footnotetext{
${ }^{6} \mathrm{Na}$ citação a seguir, os termos em língua portuguesa que se encontram em itálico estão grafados em itálico no original. Além disso, optou-se por deixar, entre colchetes, algumas expressões e palavras do original alemão, em virtude das variadas possibilidades de tradução, chamando atenção especial para uma dupla de palavras: Gewalt e Macht, sendo que a primeira pode significar tanto poder quanto violência, enquanto a segunda refere-se, necessariamente, a poder. O contexto nos leva a considerar que a tradução mais adequada para Gewalt, nessa passagem, é poder, e não violência, mas decidimos incluir essa nota a fim de explicitar o debate implícito no original.

${ }^{7} \mathrm{O}$ termo "educação física" (körperliche Erziehung) também poderia ser traduzido como "educação do corpo". Por sua vez, o termo "educação politécnica" (polytechnische Ausbildung) poderia ser igualmente traduzido como "preparação" ou "formação" politécnica.
}

\begin{tabular}{|l|l|l|l|l|}
\hline Q Rovista Dialectus & Ano 4 & n. 10 & Janeiro - Julho 2017 & p. 91-114 \\
\hline
\end{tabular}


portanto, encontra-se em um contexto de dominação e exploração. Importa-lhe, dessa forma, garantir que se protejam as crianças, evitando que o trabalho capitalista submetaas aos mesmos cerceamentos e aos malefícios provocados pelo trabalho industrial inglês do século XIX; de outro lado, há uma preocupação em ter acesso - e eis o sentido e o conteúdo da educação politécnica - às bases da produção, afinal de contas, disso dependeria inteiramente toda e qualquer possibilidade de poder organizar e controlar os processos produtivos, assumindo, em um momento futuro, um papel ativo desse ponto de vista. Isso, igualmente, constitui um elemento vital para que se possa estabelecer uma relação, mesmo que mediata, no que diz respeito aos aspectos políticos da educação - agora em Marx, à frente em Adorno.

Assim, encaminhando-nos para a argumentação de Adorno referente ao modo como a educação adquire determinada(s) forma(s), é fundamental salientar como o olhar de Marx ancora-se sobre a interpretação das relações sociais de produção em sentido amplo: isto é, referindo-se à produção de produtos - sobre a sociedade burguesa, de mercadorias - mas contemplando, igualmente, a formação e produção humanas, seja dos indivíduos, seja da sociedade como um todo. Desse modo, precisa dar conta, por exemplo, do imbricamento entre o histórico, o econômico-produtivo e o político. Tal preocupação se manifesta na crítica que Adorno faz à formação, a qual se encontra intimamente ligada às relações sociais de produção, apresentando um caráter ideológico na medida em que a promessa de emancipação geral que ela contém pressupõe condições objetivas jamais efetivadas. Por esse motivo, a formação, que permanece sendo um conceito ligado à burguesia, não atingiu a classe trabalhadora, a qual esteve submetida a um processo de semiformação contrário à emancipação. Nesse sentido, a crítica sobre a formação precisa levar em consideração não apenas os ideais construídos ao longo da história - entre eles, o de democracia - mas, também, as promessas não cumpridas devido às configurações sociais em que eles se apresentaram.

\section{Sobre a educação como formação (Erziehung als Bildung) em Theodor W. Adorno}

Na década de 1960, Adorno se fez presente no debate público sobre educação que estava ocorrendo na Alemanha. Por meio de entrevistas, palestras e debates, frequentemente transmitidos pela rádio do estado de Hessen, discutiu aspectos problemáticos da sociedade de seu tempo, assim como possibilidades de transformação da realidade a partir do âmbito educacional. Tais debates foram transcritos e publicados

\begin{tabular}{|l|l|l|l|l|}
\hline Gonista Dialectus & Ano 4 & n. 10 & Janeiro - Julho 2017 & p. 91-114 \\
\hline
\end{tabular}


e podem ser encontrados na edição intitulada Educação e emancipação, a qual será objeto principal da presente seção.

As posições assumidas por Adorno nas discussões educacionais dos anos de 1960 revelam a maturidade de um pensamento que se nutriu das experiências vividas e fez delas o solo para uma crítica dura e rigorosa em relação ao seu tempo. Ainda que as promessas trazidas pelo marxismo tenham sido em grande parte matizadas, sobretudo na medida em que a crítica dialética ao esclarecimento revelou as contradições com que a razão está necessariamente entrelaçada e que a barbárie foi vivenciada, o pensamento não sucumbiu às tendências de reificação, mantendo diante de si uma esperança consciente de seus limites para transformar a realidade.

Desse ponto de vista, é relevante apontar o fato de que a reflexão de Adorno, tal qual proposta no âmbito do Instituto de Pesquisa Social, contempla elementos oriundos da psicologia social de Sigmund Freud, que visam melhor interpretar e, assim, pensar a transformação da relação de condicionamento mútuo entre indivíduo e sociedade. Para isso, mesmo que implicitamente, a questão da história e da natureza apresenta-se como um elemento relevante, sobretudo considerando-se a ideia de distanciar-se da concepção engessada e imutável de natureza humana, destacando a historicidade do social, e que, em especial, tem como uma - se não a principal - chave de leitura a educação. Tal posição fica explícita na afirmação de Adorno de que "um dos momentos do estado de consciência e de inconsciência daninhos está em que seu ser-assim - que se é de um determinado modo e não de outro - é apreendido equivocadamente como natureza, como um dado imutável e não como resultado de uma formação" (Adorno, 1995a [1967], p. 132). No momento em que desenvolve essa interpretação, à luz do processo de reconstrução da Alemanha no contexto do pós-guerra, torna-se evidente o quanto há um olhar arguto voltado a pensar a questão da democracia.

Ao observarmos brevemente os títulos conferidos aos debates como, por exemplo, Educação após Auschwitz, Educação e emancipação, A educação contra a barbárie ou Educação - para quê?, podemos ser levados a pensar que Adorno se dedicará à reflexão sobre as finalidades da educação, dentre as quais, possivelmente a emancipação, contra um estado de barbárie representado por Auschwitz. Essas primeiras impressões poderão ser verificadas ao longo da leitura dos textos, mas será preciso afastar uma interpretação ingênua de que a educação, por si só, poderia conduzir à emancipação ou garantir a democracia. Para entender por que essa ideia não contradiz a confiança que Adorno deposita na formação, examinemos suas considerações sobre o

\begin{tabular}{|l|l|l|l|l|}
\hline Q Ronista Dialectus & Ano 4 & n. 10 & Janeiro - Julho 2017 & p. 91-114 \\
\hline
\end{tabular}


tema à luz da centralidade que a emancipação adquire no âmbito do seu pensamento, sempre distanciada de uma concepção idealista.

Na conferência Educação após Auschwitz, Adorno é enfático:

[...] a exigência que Auschwitz não se repita é a primeira de todas para a educação. De tal modo ela precede quaisquer outras que creio não ser possível nem necessário justificá-la. Não consigo entender como até hoje mereceu tão pouca atenção. Justificá-la teria algo de monstruoso em vista de toda monstruosidade ocorrida. Mas a pouca consciência existente em relação a essa exigência e as questões que ela levanta provam que a monstruosidade não calou fundo nas pessoas, sintoma da persistência da possibilidade de que se repita no que depender do estado de consciência e de inconsciência das pessoas. Qualquer debate acerca de metas educacionais carece de significado e importância frente a essa meta: que Auschwitz não se repita. Ela foi a barbárie contra a qual se dirige toda a educação. Fala-se da ameaça de uma regressão à barbárie. Mas não se trata de uma ameaça, pois Auschwitz foi a regressão; a barbárie continuará existindo enquanto persistirem no que têm de fundamental as condições que geram esta regressão. É isso que apavora (Adorno, 1995a [1967], p. 119).

Gostaríamos de destacar, na passagem acima, pelo menos dois aspectos que são fundamentais para se entender o papel da educação de acordo com Adorno. Em primeiro lugar, há a defesa de que a educação deve se voltar contra a repetição da barbárie. Essa tarefa não se apresenta como objetivo, mas como exigência moral. A barbárie, porém, é compreendida a partir da interpretação proposta por Freud em relação às origens do mal-estar na sociedade (e na cultura), a qual permite a Adorno concluir que "se a barbárie encontra-se no próprio princípio civilizatório, então pretender se opor a isso tem algo de desesperador" (Adorno, 1995a [1967]: 120). Isso porque as condições que tornaram Auschwitz possível se encontram no plano objetivo - são condições econômicas e sociais específicas, o que permite sustentar a importância de se observar o lado material -, mas não elimina o fato de haver também condições subjetivas, as quais dizem respeito aos processos psicológicos que levaram os indivíduos a sustentar o sistema. Desse modo, vincular a possibilidade de resistência à barbárie ao âmbito da educação seria pensar de forma ingênua e reducionista, já que deixaria intocadas as condições sociais e econômicas tão centrais e determinantes para a compreensão desse fenômeno. Todavia, o quid pro quo permanece, pois se a transformação da realidade não se coloca no horizonte da práxis atual, o que nos resta, então? Para buscarmos uma

\begin{tabular}{|l|l|l|l|l|}
\hline Gonista Dialectus & Ano 4 & n. 10 & Janeiro - Julho 2017 & p. 91-114 \\
\hline
\end{tabular}


resposta a essa questão cabe trazer, aqui, outra passagem da conferência proferida por Adorno:

[...] como hoje em dia é extremamente limitada a possibilidade de mudar os pressupostos objetivos, isto é, sociais e políticos que geram tais acontecimentos, as tentativas de se contrapor à repetição de Auschwitz são impelidas necessariamente para o lado subjetivo. Com isto refiro-me sobretudo também à psicologia das pessoas que fazem coisas desse tipo (Adorno, 1995a [1967], p. 121).

Insistir em uma ação dirigida à dimensão subjetiva significa compreender, por exemplo, como e por quais motivos as pessoas adotam comportamentos de identificação com o poder totalitário. Tal esclarecimento seria um primeiro passo em direção à autorreflexão que é necessária ao movimento de resistência à barbárie. Nesse sentido, a educação teria um caráter político, estando motivada e comprometida com a resistência ao totalitarismo pela formação da consciência dos sujeitos. Isso significa formar para a emancipação, para um pensar refletido e autônomo. Se a barbárie permanece como ameaça, é preciso trabalhar no sentido de evitar que seus pressupostos se fortaleçam. No âmbito subjetivo, então, Adorno enfatizará a necessidade de "reconhecer os mecanismos que tornam as pessoas capazes de cometer tais atos, é preciso revelar tais mecanismos a eles próprios, procurando impedir que se tornem novamente capazes de tais atos, na medida em que se desperta uma consciência geral acerca desses mecanismos" (Adorno, 1995a [1967], p. 131).

A insistência em um pensamento que fortaleça no sujeito a resistência contra a reificação significará, para Adorno, a possibilidade e sentido da própria práxis, a qual, se por um lado, também é afetada pelas relações distorcidas que a sociedade produz, por outro, justifica-se pela necessidade de se opor à barbárie (Cf. Adorno, 1995b, p. 214). Para Adorno, não se trata de buscar uma identidade entre teoria e práxis, mas de preservar a autonomia do pensamento que, enquanto exercício crítico, pode apontar para as contradições da sociedade, constituindo-se um elemento de negação e resistência. Dessa forma, o pensar adquire um caráter de transformação do sujeito e expressa sua afinidade com a práxis.

Essa indicação, porém, deve ser compreendida no contexto da crítica feita por Adorno à sociedade de seu tempo, a qual é marcada pela reificação e pelo predomínio de tendências que se dirigem exatamente contra a formação do sujeito. Apesar da crescente democratização do ensino e do acesso aos bens culturais, a formação se

\begin{tabular}{|l|l|l|l|l|}
\hline Gonista Dialectus & Ano 4 & n. 10 & Janeiro - Julho 2017 & p. 91-114 \\
\hline
\end{tabular}


apresenta apenas como promessa, uma vez que as condições para sua realização não podem ser satisfeitas em uma sociedade desigual. Em seu texto Teoria da semiformação, Adorno defende que a formação teve sua origem com a ascensão da burguesia no século XVIII, servindo a ela como instrumento de afirmação na medida em que possibilitava a preparação dos indivíduos para o desempenho de atividades administrativas e econômicas que os colocava em uma situação de vantagem em relação aos camponeses. O conceito de formação, o qual seria, na leitura de Adorno, mais uma condição para a consolidação da burguesia do que seu privilégio, expressaria um ideal de sociedade racional, constituída por indivíduos livres e iguais. Contudo, tal ideal logo se mostraria falsificado, uma vez que a formação se restringiu apenas à burguesia e aquela promessa de emancipação se revelaria inalcançável, dado que as condições objetivas não estavam dadas. Por essa razão, o conceito de formação apresenta um caráter ideológico, pois se baseia na promessa "de que ela poderia extrair de si mesma e dar aos homens o que a realidade lhes recusa" (Adorno, 2010 [1959]: 13).

Os trabalhadores, cuja vida se dava em condições objetivas bem diversas, não puderam experienciar a formação tal como foi possível à burguesia. Para eles, o contato com a cultura ocorreu na forma de uma integração, ou seja, como um processo pelo qual os bens culturais se tornaram acessíveis, porém, com um conteúdo adaptado às necessidades do mercado e da própria consciência que precisava ser neutralizada. Surge, então, o fenômeno que Adorno chama de semiformação (Halbbildung), o qual nega a própria formação na medida em que a ideia de autonomia se distancia tanto de seus pressupostos quanto de seus objetivos. Nesse sentido, inclusive, Adorno afirma: "não foi por acaso que os socialistas alcançaram sua posição chave na história baseando-se na posição econômica objetiva, e não no contexto espiritual” (Adorno, 2010 [1959], p. 14). O proletariado, portanto, em função das condições materiais de sua existência, obrigado a longas jornadas de trabalho, não pôde participar do movimento de formação que possibilitou à burguesia desenvolver uma consciência de si que a colocou em uma situação privilegiada.

O fenômeno da semiformação passa a ser, para Adorno, a tendência predominante na sociedade. As massas podem contar com o acesso aos bens culturais, privadas, porém, das condições - como o próprio ócio - para uma relação apropriada e formativa. A indústria cultural, como fenômeno correlato, contribui para esse novo modo de formação da consciência. Ela sustenta a promessa de que pela democratização da cultura é possível alcançar a formação, quando, na realidade, transforma a própria

\begin{tabular}{|l|l|l|l|l|}
\hline Qevista Dialectus & Ano 4 & n. 10 & Janeiro - Julho 2017 & p. 91-114 \\
\hline
\end{tabular}


cultura em mercadoria. Há uma integração subjetiva entre as classes, já que todos podem ter acesso aos bens culturais, mas, objetivamente, a formação é negada pela impossibilidade de sua verdadeira apropriação. Assim, a semiformação acaba por fortalecer o fenômeno da reificação, constituindo-se em um obstáculo para a transformação da sociedade em direção à sua emancipação.

A educação, a partir dessa perspectiva, encontra-se em uma situação paradoxal: dirigir-se à emancipação em uma sociedade que nega as condições para que ela se realize. Tal dificuldade irá se refletir na possibilidade da sociedade se organizar democraticamente. Uma sociedade democrática deveria ser formada a partir da liberdade e autonomia dos indivíduos. Por isso, se a reificação é uma tendência objetiva, ela impede que a democracia se afirme como expressão de indivíduos emancipados. De acordo com Adorno, “[...] a ideologia dominante hoje em dia define que, quanto mais as pessoas estiverem submetidas a contextos objetivos em relação aos quais são impotentes, ou acreditam ser impotentes, tanto mais elas tornarão subjetiva esta impotência" (Adorno, 1995b [1959], p. 36). Desse modo, atribui-se ao indivíduo algo que, na verdade, tem raízes sociais e objetivas, as quais seguem intocadas e imunes à crítica. No plano subjetivo, a impotência individual face à realidade é reforçada pela indústria cultural. Com o objetivo de entretenimento e diversão, os bens culturais preenchem o tempo livre dos indivíduos, reproduzindo a mesma lógica subjacente à organização do trabalho. Para Adorno:

[...] a ordem econômica e, seguindo seu modelo, em grande parte também a organização econômica, continuam obrigando a maioria das pessoas a depender de situações dadas em relação às quais são impotentes, bem como a se manter numa situação de não-emancipação. Se as pessoas querem viver, nada lhes resta senão se adaptar à situação existente, se conformar; precisam abrir mão daquela subjetividade autônoma a que remete a ideia de democracia; conseguem sobreviver apenas na medida em que abdicam de seu próprio eu. Desvendar as teias do deslumbramento implicaria um doloroso esforço de conhecimento que é travado pela própria situação da vida, com destaque para a indústria cultural intumescida como totalidade. A necessidade de uma tal adaptação, da identificação com o existente, com o dado, com o poder enquanto tal, gera o potencial totalitário (Adorno, 1995b [1959], p. 43).

É nesse contexto que a preocupação com uma educação que forme uma subjetividade resistente ao poder totalitário se coloca. As conclusões a que chegaram

\begin{tabular}{|l|l|l|l|l|}
\hline Q Ronista Dialectus & Ano 4 & n. 10 & Janeiro - Julho 2017 & p. 91-114 \\
\hline
\end{tabular}


Adorno e Horkheimer em suas pesquisas sobre a personalidade autoritária subjazem aos comentários de Adorno nas conferências a que temos feito referência. O caráter autoritário pode ser associado a uma subjetividade fraca, a qual se identifica com formas de poder que se expressam, por exemplo, nas imagens oferecidas pela indústria cultural. Assim, um indivíduo cuja subjetividade foi formada de um modo frágil, seria incapaz de exercer a autonomia, de refletir sobre si próprio e sobre sua conduta, de opor resistência à dominação, adaptando-se facilmente ao poder que vem do exterior. Segundo Adorno,

[...] pesquisas feitas nos Estados Unidos revelaram que esta estrutura da personalidade não se relaciona tanto assim com critérios econômico-políticos. Ela seria definida muito mais por traços como pensar conforme as dimensões de poder impotência, paralisia e incapacidade de reagir, comportamento convencional, conformismo, ausência de auto-reflexão, enfim, ausência de aptidão à experiência. Personalidades com tendências autoritárias identificam-se ao poder enquanto tal, independente de seu conteúdo. No fundo dispõem só de um eu fraco, necessitando, para se compensarem, da identificação com grandes coletivos e da cobertura proporcionada pelos mesmos (Adorno, 1995b [1959], p. 36).

Um indivíduo que possui o "eu fraco" não se reconhece exatamente como sujeito, estendendo essa compreensão distorcida aos outros, os quais passam a ser vistos como algo que pode ser dominado e manipulado. Identificam-se facilmente com as imagens associadas aos coletivos, que promovem uma falsa integração, fundada sobre a necessidade de preencher esse vazio de autoridade próprio a tal indivíduo. Para Adorno, "no começo as pessoas desse tipo se tornam por assim dizer iguais a coisas. Em seguida, na medida em que o conseguem, tornam os outros iguais a coisas" (Adorno, 1995a, p. 130). Aqui se pode identificar com clareza a proximidade com o pensamento de Marx, sobretudo aquele presente em O capital (1961 [1872]). Ali, ao final do capítulo 1, intitulado "A mercadoria", Marx traz em seu último item o conceito do "fetichismo da mercadoria". Ele visa expressar um processo que leva as relações sociais a serem, em um contexto em que a sociedade se organiza por meio (da troca) das mercadorias, mediadas pelas coisas - notadamente, pelas mercadorias - e, por sua vez, as relações entre as coisas passam a ser vistas como relações sociais.

Ainda que a obra de Marx, até mesmo em virtude do momento no qual foi escrita, não tenha podido incorporar elementos psicanalíticos ao seu argumento, o modo

\begin{tabular}{|l|l|l|l|l|}
\hline Q Ronista Dialectus & Ano 4 & n. 10 & Janeiro - Julho 2017 & p. 91-114 \\
\hline
\end{tabular}


pelo qual ocorre o movimento do capital, a sua lógica de reprodução e acumulação, traz consigo uma ideia de reificação. No contexto autoritário específico observado por Adorno, esse viés ganha outra forma e se expressa, portanto, nos mecanismos utilizados para subjugar uma determinada sociedade. O caráter manipulador pode ser, então, associado à consciência reificada, à impossibilidade de realizar uma experiência não vinculada à dominação, e é por isso que a educação deve se voltar contra ela, procurando evitar que aquele tipo de personalidade se constitua. Adorno considera duas dimensões pelas quais isso se torna possível: atuando-se com cautela no período da infância, em que a influência sobre o caráter pode ser mais fundante, e trabalhando-se no sentido do esclarecimento geral dos indivíduos.

Apesar de Adorno se eximir de indicar de forma concreta um projeto educacional que atenda a essas exigências, aponta determinadas ações que contribuiriam para uma educação contra a barbárie. Em relação à educação na primeira infância, a preocupação estaria em não fomentar atitudes de competição entre as crianças, em não educar para a severidade, para a frieza, qualidades essas que contribuem para os estados de alienação e insensibilidade próprias do caráter manipulador. Para Adorno, "o elogiado objetivo de 'ser duro' de uma tal educação significa indiferença contra a dor em geral" (Adorno, 1995a [1967], p. 128). Adorno cita, também, a presença de rituais como uma forma negativa de adaptação do indivíduo à coletividade, pois tanto fortalecem o poder dos grupos ao preço do enfraquecimento do indivíduo, quanto lhe infligem dor, exercendo uma violência em nome dos "costumes" admitidos socialmente. Para ele, “o elogiado objetivo de 'ser duro' de uma tal educação significa indiferença contra a dor em geral" (Adorno, 1995a [1967], p. 128), algo que precisa ser transformado, pois a consequência é que nesse comportamento "[...] nem se diferencia tanto a dor do outro e a dor de si próprio. Quem é severo consigo mesmo adquire o direito de ser severo também com os outros, vingando-se da dor cujas manifestações precisou ocultar e reprimir" (Adorno, 1995a [1967], p. 128).

A outra dimensão, a do esclarecimento do público, leva em consideração elementos já destacados anteriormente, como, por exemplo, a necessidade de promover a autorreflexão do sujeito, de buscar, também, compreender as raízes do caráter autoritário, inclusive com pesquisas empíricas que visem identificar os elementos característicos desse tipo de personalidade. Há que se insistir no trabalho da memória e de elaboração do passado para tornar claros os pressupostos que possibilitaram a barbárie e, assim, evitar que ela se repita. O esclarecimento deve se direcionar à opinião

\begin{tabular}{|l|l|l|l|l|}
\hline Q Ronista Dialectus & Ano 4 & n. 10 & Janeiro - Julho 2017 & p. 91-114 \\
\hline
\end{tabular}


pública a fim de fazer com que os indivíduos reflitam não apenas sobre o que aconteceu, mas também sobre si próprios, e sejam capazes de tomar consciência sobre suas ações para que não reproduzam, ainda que inconscientemente, as relações de poder e de dominação tão enraizadas socialmente.

Tais medidas constituiriam uma educação política que se concentra na formação subjetiva para promover a emancipação. Conservam, por isso, uma afinidade com a práxis no sentido de que refletir e pensar de forma crítica e dialética se colocam como modos de se opor à dominação social. A educação assim concebida, nos termos de uma formação, é também fundamental para o fortalecimento da democracia, a qual necessita de indivíduos autônomos para cumprir suas promessas. Aliás, é justamente por não realizar suas promessas que a sociedade democrática, segundo Adorno, alimenta nos indivíduos uma hostilidade contra si própria. Para ele, o poder totalitário

[...] é reforçado pela insatisfação e pelo ódio, produzidos e reproduzidos pela própria imposição à adaptação. Justamente porque a realidade não cumpre a promessa de autonomia, enfim, a promessa de felicidade que o conceito de democracia afinal assegurara, as pessoas tornam-se indiferentes frente à democracia, quando não passam até a odiá-la. A forma de organização política é experimentada como sendo inadequada à realidade social e econômica; assim como existe a obrigação individual à adaptação, pretende-se que haja também, obrigatoriamente, uma adaptação das formas de vida coletiva, tanto mais quando se aguarda de uma tal adaptação um balizamento do Estado como megaempresa na aguerrida competição de todos. Os que permanecem impotentes não conseguem suportar uma situação melhor sequer como mera ilusão; preferem livrar-se do compromisso com uma autonomia em cujos termos suspeitam não poder viver, atirando-se no cadinho do eu coletivo (Adorno, 1995b [1959], p. 44).

É tarefa da formação romper com a impotência originada pela estrutura social e que se apresenta ao sujeito como impossibilidade de resistência. $\mathrm{O}$ fato de o indivíduo poder agir de maneira violenta contra outras pessoas e contra si é algo que, em tese, poderia ser visto como conflituoso com a sua própria natureza. Logo, o potencial destrutivo que se observa tão somente pode ser interpretado por meio da forma social articulada pelo capital. A seguir, visamos articular um dos papeis atribuído à filosofia de uma perspectiva histórico-materialista e inserida no processo formativo concebido no âmbito da teoria crítica, que dialoga explicitamente com a busca da democracia.

\begin{tabular}{|l|l|l|l|l|}
\hline Qevista Dialectus & Ano 4 & n. 10 & Janeiro - Julho 2017 & p. 91-114 \\
\hline
\end{tabular}




\section{O aspecto formativo da educação e um de seus papeis para a democracia}

Se nos escritos de Adorno se fizeram presentes menções à educação em sentido mais amplo e geral, os textos que recuperamos nesta parte de nosso artigo focam, de um lado, o pensamento de Marx e, de outro, o papel do estudo da filosofia. O primeiro é um artigo de Alfred Schmidt, originalmente publicado em 1966, que apresenta uma reflexão dirigida direta e pormenorizadamente a como no pensamento de Marx - distinguindo-o, portanto, também de Engels - está presente uma concepção de natureza e história. Ele discute a historicização do social e o faz recorrendo ao processo que optamos por denominar: historicização (e socialização) da natureza. O segundo tem por base uma fala de Horkheimer, que foi transcrita e retrabalhada por ele, datando de 1967.

Schmidt explicitamente recusa o argumento de que se encontraria, no olhar e na análise de Marx, alguma forma de evolucionismo, atingindo, notadamente, a sua concepção e teoria da história, como se observa no trecho a seguir: "O curso da história é, portanto, para Marx muito menos linear do que se supõe comumente; ele não segue nenhuma ideia com sentido unitário, mas compõe-se de processos individualizados que se dão permanentemente" (Schmidt, 1977 [1966], p. 249). O aspecto individual é aquele voltado à prática humana. Ao mesmo tempo, cabe lembrar que nunca se trata de seres humanos efetivamente isolados uns dos outros, podendo suas ações tão somente serem compreendidas quando consideramos os contextos de socialização. Schmidt salienta haver um papel central atribuído à sociedade burguesa que, na perspectiva de Marx, assume a tarefa de ruptura e transformação muito próxima, em termos de alcance, àquela que distingue ser humano e natureza, consubstanciada no conceito sociedade.

Marx quer chegar aqui ao seguinte: todo confronto entre ser humano e natureza que ultrapassa as formas animais rudimentares acontece nos quadros de uma forma determinada de sociedade, mas cada uma dessas formas não é 'sociedade' no sentido de burguesa, de sociedade par excellence. (Schmidt, 1977 [1966], p. 249 - aspas no original).

Voltando à Ideologia alemã, de modo semelhante ao que ocorre em sua obra do 18 Brumário, Marx enxerga a forma limitada da democracia como a expressão do domínio de classe. Isso, efetivamente, está longe de implicar o abandono por completo da democracia em seus escritos: antes, o que ele busca é evitar que tais formas abstratas e reificadas de democracia, tal qual se fizeram presentes no contexto em que ascende a sociedade civil (burguesa), mas em que permanece a exploração, passassem a ser vistas

\begin{tabular}{|l|l|l|l|l|}
\hline Qevista Dialectus & Ano 4 & n. 10 & Janeiro - Julho 2017 & p. 91-114 \\
\hline
\end{tabular}


como a realização da liberdade e dos potenciais humanos. Um dos pontos que reforçava a separação indivíduo e sociedade era a organização dos interesses.

Justo, pois, os indivíduos apenas buscam o seu interesse particular, que para eles não coincide com o social, aliás, é uma forma geral e ilusória da comunidade [Gemeinschaftlichkeit], isso lhes é validado como algo 'estranho' e 'independente' deles, isto é, como um interesse 'geral' que é, ele próprio, particular e característico, ou eles mesmos precisem se mover nesse conflito como na democracia (Marx e Engels, 1958 [1845-1846], p. 34 aspas e itálico no original).

O modo como há, aqui, a referência ao conflito sob a democracia expressa, precisamente, a impossibilidade de conciliar os interesses, significando a perda de uma referência do geral - a saber, do social. Como veremos a seguir, esse é um aspecto que percorre as diferentes abordagens, aparecendo, igualmente, nas reflexões de Horkheimer ao dirigir-se ao âmago de alguns elementos de como a educação superior se organizava no âmbito dessa sociedade. Assim, se naquele momento Marx e Engels refletem acerca de relações humanas num sentido amplo, no século XX o olhar se volta ao recorte mais específico da educação institucionalizada, sobretudo considerando que ela é vista como um vetor fundamental de democratização.

Assim, em Horkheimer, localizando suas reflexões no contexto dos protestos estudantis, observa-se a preocupação em pensar como a universidade crítica - uma proposta que se desenhava à época no corpo estudantil - poderia e precisaria se dirigir a garantir espaço para o que ele denomina uma "vida democrática". Ele nota haver, inclusive, um equívoco ao se pensar em termos de "ciências humanas", visto que isso expressa a tentativa de perseguir o ideal das ciências naturais, e remete a como há, no francês, as variações das Belles-Lettres ou das Humanités, que explicitam um olhar completamente distinto.

É possível transformar a formação acadêmica [akademische Bildung] no sentido de reflexão crítica? Pensar acerca de questões políticas, sociais, sobre a realização de uma vida verdadeiramente democrática, a relação com outros países, a instituição do mundo ocidental, a relação com o restante do mundo, é um tema apenas para políticos, e não para as instituições da formação, sobretudo as de educação superior [Hochschulen]? (Horkheimer, 1989 [1967a], p. 87). 
Horkheimer frisa que está longe de querer alimentar a ilusão de ser um problema interno à formação humana em nível superior, indicando tratar-se de entraves sociais muito mais amplos. Logo, de modo semelhante ao que temos em Adorno, insere a crítica que leva a cabo nesse tempo e espaço históricos em que a universidade e a educação superior passam por transformações e, inclusive, demonstram sua inadequação para a formação de seres humanos que sejam capazes de colocar em questão e problematizar a realidade. É necessário atentar, porém, à dinâmica - ou a sua falta - na relação entre essas diferentes formas de conhecimento que organizam a educação superior. Evitar, portanto, que ela se veja restrita a algo pré-moldado, estático, engessado, dificultando que haja o desenvolvimento da reflexão em sentido forte.

A história na universidade, sobre a qual está fundada a aula na escola, visa a exatidão, refere-se às fontes, aos documentos. Com razão. Mas sem a psicologia e a sociologia, insuficientemente presentes nos arquivos, a sua compreensão [Verständnis] permanece modesta (Horkheimer, 1989 [1967a], p. 90).

Relacionando-se a maneira de organizar o social desenhada por Marx, quando busca apreender as formas contraditórias de manifestação do capital que levam os antagonismos supracitados a se aprofundarem cada vez mais, à perspectiva aqui posta por Horkheimer, pode-se identificar esses processos como consequência de uma forma específica de desenvolvimento histórico, ou seja, que efetivamente constituem produtos do social. A noção de um sujeito - seja ele o capitalista, o empresário, o industrial, seja, conforme encontramos na teoria de Marx, o próprio capital - implica, dado que a automediação passa a ocupar um segundo plano no âmbito da sociedade burguesa, uma espécie de ruptura na maneira de encarar o processo de formação humana.

Ela depende, inextricavelmente, da relação entre teoria e prática citada ao longo de nosso artigo e que, aqui, retomamos na interpretação exposta por Schmidt. Desse ponto de vista, Schmidt é taxativo ao delinear os limites e os alcances da tentativa de interpretar e transformar a realidade, conforme pode ser identificada e ainda apropriada a partir das reflexões esboçadas por Marx, sem dúvida também influenciado por autores como Adorno e Horkheimer, com os quais Schmidt teve aula e pelos quais foi orientado durante a sua carreira acadêmica.

Sempre, pois, a consciência enquanto espírito ativo penetra na realidade por ela reproduzida. A tarefa do conhecimento é não capitular diante desta realidade que se coloca ao redor dos seres

\begin{tabular}{|l|l|l|l|l|}
\hline Q Povista Dialectus & Ano 4 & n. 10 & Janeiro - Julho 2017 & p. 91-114 \\
\hline
\end{tabular}


humanos como um muro de pedras. $\mathrm{Na}$ medida em que o conhecimento revive os processos históricos humanos apagados nos fatos constituídos, ele revela a realidade como algo produzido pelo ser humano e, portanto, mutável: a prática [Praxis], enquanto conceito mais importante do conhecimento, transforma-se em ação política. (Schmidt, 1977 [1966], p. 258).

Pode-se identificar, portanto, um duplo processo de transformação: de um lado, a expressão da teoria, do conhecimento por meio da prática; de outro, e concomitantemente, a transformação do ser humano. É precisamente esse o sentido que encontramos no decorrer da discussão acerca da educação, e que, vale salientar, apresenta um duplo aspecto, pois ela exerce papel fundamental na constituição dos seres humanos enquanto seres sociais e, na mesma medida em que contribui para reproduzir a cultura e determinadas estruturas sociais existentes, também pode ser apropriada com o objetivo de provocar mudanças conscientizadoras que se encaminhem para a emancipação.

\section{Considerações finais:}

O intuito deste texto foi indicar laços e continuidades entre os diferentes olhares sobre os processos formativos e de constituição humana e da sociedade, ancorados no olhar da teoria crítica conforme o autoentendimento que é esboçado nos primórdios da Escola de Frankfurt, e que inclui a abordagem de Marx nessa linhagem. O eixo fundamental da reflexão concerne os pressupostos e condicionantes das possibilidades e das formas concretas que levam à mudança e à transformação social, daí a relevância da educação política. Se em Marx e Schmidt a ênfase recai sobre o trabalho e a história, em Adorno e Horkheimer o tema é a educação pensada em termos mais amplos a partir da ideia de formação, e o fio condutor que os aproxima é a relação entre processos de individuação e de socialização, centrando esforços num mundo e em um contexto histórico de ruptura e reconstrução.

Essa linha de raciocínio fundamenta um determinado viés epistemológico que confere à teorização desses diferentes autores um olhar político. Aqui, obviamente, esse termo deve ser entendido enquanto caracterizando uma determinada prática humana e, consequentemente, distingue-se de uma redução à política tal qual a conhecemos em sentido institucionalizado, sem impedir que possa ocorrer alguma aproximação. O cerne do sentido de político é a prática - para a qual, conforme salientamos diversas vezes, a

\begin{tabular}{|l|l|l|l|l|}
\hline Q Ronista Dialectus & Ano 4 & n. 10 & Janeiro - Julho 2017 & p. 91-114 \\
\hline
\end{tabular}


teoria desempenha um papel vital - voltada à emancipação. Logo, a educação e o trabalho devem ter, no horizonte de sua atuação, um sentido que busque transformar as relações sociais dadas, estruturando-as de maneira a enfrentar formas de dominação e de exploração historicamente fundadas, problematizando-as como se tivessem origens naturais, expressando os condicionantes sociais de sua produção e reprodução.

Por mais que este não seja o lugar de propor uma teoria pedagógica, filosófica ou sociológica, certamente podemos refletir brevemente acerca de sugestões por meio das quais se possa efetivar o processo de conscientização, no sentido especificamente político, que busca enfrentar o avanço da reificação identificada por Adorno. A título de exemplo, observa-se que existe a possibilidade, no contexto brasileiro, de se colocar em questão e discutir longamente os fundamentos sociológicos, políticos e jurídicos que provocaram a longa persistência de homenagens a generais e marechais do contexto do regime militar autoritário do pós-1964, por meio da nomenclatura de diversas obras públicas, tais como "ponte Costa e Silva", "rodovias Dutra e Castello Branco", e por daí em diante, sobretudo identificando e discutindo criticamente os mecanismos que permitiram esse tipo de reconhecimento em um contexto democrático.

O que está tematizado por Horkheimer e Adorno, desde as suas reflexões que lidaram com a experiência do extermínio humano cuidadosamente planejado, e que é apresentado, entre outros textos, na Dialética do esclarecimento, ainda durante os anos 1940, e duas décadas depois, nos textos de Adorno e Horkheimer aqui abordados, expressa o quanto esse processo pode ser enganoso. Daí, também, o motivo que faz com que o exercício e a prática de uma educação política - que tenha como pano de fundo e objetivo a democracia em sentido forte do termo, para além de seu entendimento tão somente representativo - se apresente como processo contínuo, que deve ser praticado muito além de contextos autoritários, justamente trabalhando a fim de evitar que as formas de organização política e a mentalidade predominante se orientem para isso.

Horkheimer chama a atenção para esse aspecto ao afirmar:

[...] nossa tarefa é assegurar que, no futuro, a capacidade para a teoria e para a ação que dela deriva nunca desapareça novamente, mesmo em um período vindouro de paz em que a rotina diária pode tender a permitir que todo o problema seja uma vez mais esquecido. Nossa tarefa é lutar continuamente para evitar que a humanidade se torne completamente abatida pelos terríveis acontecimentos do presente, evitar que a crença humana em uma direção valiosa, pacífica e feliz para sociedade se extinga da terra (Horkheimer, 1939/1940, p. 337). 
As relações e os movimentos dialéticos, que, nas formas sociais analisadas por Marx, assumem expressões contraditórias e antagônicas, estão marcadas pelo desenvolvimento do ser humano de determinada maneira. Isso é derivado da observação empírica, como registrado desde A ideologia alemã, sendo que o significado disso é apreender como se dão as mudanças históricas e, inclusive, incorporar à teoria e à epistemologia a consideração dessa miríade de elementos históricos e sociais. É também dessa perspectiva, de um tratamento que tenha fundamentos teóricos, mas que atente às suas expressões e implicações práticas, que consideramos ser relevante lançar mão das perspectivas de Horkheimer e Adorno, a fim de permitir aprofundar as reflexões acerca da constituição social da humanidade nesse duplo sentido: a formação de indivíduos que se posicionem criticamente face à obtusidade do real, que saibam resistir, quando isso se mostrar necessário, porém, que também contribuam ativamente para transformar essa realidade social, quando houver espaços, em sentido democrático, identificando os conflitos e antagonismos postos.

Agradecimentos: $O$ artigo contou com o apoio financeiro da CAPES sob a forma de bolsa de estágio pós-doutoral a XXXXXXXXXXXXXXXXXX, processo n. XXXXX.

\section{Referências:}

ADORNO, Th. W. Educação após Auschwitz. In: Rio de Janeiro: Paz e Terra, 1995a [1967], pp. 119-138.

Educação e emancipação.

Notas marginais sobre teoria e práxis. In: Palavras e sinais: modelos críticos 2. Petrópolis: Vozes, 1995 b.

Teoria da semiformação. In: PUCCI, B.; ZUIN, A. A. S. e LASTÓRIA, L. A. C. N. (Orgs.). Teoria Crítica e Inconformismo: novas perspectivas de pesquisa. Campinas: Autores Associados, 2010 [1959], pp. 7-40.

HORKHEIMER, M. Geschichte des Materialismus. In: Horkheimer Gesammelte Schriften. Vol. 13. Frankfurt am Main: Fischer, 1989 [1957], pp. 397-451

The Social Function of Philosophy. In: Studies in Philosophy and Social Science, VIII, 1939-1940, pp. 322-337.

Zum Philosophiestudium heute. In: Horkheimer Gesammelte Schriften. Vol. 13. Frankfurt am Main: Fischer, 1989 [1967a], pp. 84-95.

Wissenschaft, Wahrheit und Bildung. In: Horkheimer Gesammelte Schriften. Vol. 13. Frankfurt am Main: Fischer, 1989 [1967b], pp. 174-182. 
HORKHEIMER, M. e ADORNO, Th. W. Dialektik der Aufklärung. Frankfurt am Main: Fischer, 1991 [1944/1947].

JAY, M. Dialektische Phantasie. Frankfurt am Main: Fischer, 1991 [1973].

MARX, K. O 18 Brumário de Luís Bonaparte. São Paulo: Boitempo, 2011 [1852]).

Instruktionen für die Delegierten des Provisorischen Zentralrats zu den einzelnen Fragen. In: e ENGELS, Fr. Marx-Engels-Werke. Berlim: Dietz, 1962, v. 16, pp. 190-199 [trad. bras.: MARX, K. e ENGELS, Fr. Textos sobre educação e ensino. São Paulo, Moraes, 1992 [1866], pp. 59-61].

Das Kapital. Marx-Engels-Werke. v. 23. Berlin: Dietz, 1961 [1872] [trad. bras.: O capital. Rio de Janeiro, Civilização Brasileira, 1968].

MARX, K. e ENGELS, Fr. Thesen über Feuerbach. In: . e MarxEngels-Werke. Berlin: Dietz, 1958 [1845], v. 3, pp. 533 e 534 [trad. bras.: Teses sobre Feuerbach In: A ideologia alemã. Rio de Janeiro: Civilização Brasileira, 2007, pp. 2729].

. e __. Die Deutsche Ideologie. Marx-Engels-Werke, v. 3. Berlin: Dietz, 1958 [1845-1846] [trad. bras.: A ideologia alemã. Boitempo: São Paulo, 2007].

. e Manifesto do Partido Comunista. In: Estudos Avançados. São Paulo: USP, 12 (34), 1998 [1848], pp. 7-46.

SCHMIDT, A. História e natureza em Marx. In: COHN, G. (Org.). Sociologia: para ler os clássicos. Rio de Janeiro/São Paulo: Livros técnicos e científicos, 1977 [1966], pp. 240-258.

WIGGERSHAUS, R. A Escola de Frankfurt: história, desenvolvimento teórico, signifição política. Rio de Janeiro: DIFEL, 2002 [1986].

\begin{tabular}{|l|l|l|l|l|}
\hline Qevista Dialectus & Ano 4 & n. 10 & Janeiro - Julho 2017 & p. 91-114 \\
\hline
\end{tabular}

